\title{
Correlation of rs749292 and rs700518 polymorphisms in the aromatase gene (CYP19A1) with osteoporosis in postmenopausal Polish women
}

\author{
Adam Kamiński ${ }^{1, A, D, E}$, Anna Bogacz $2,3, C, E$, Małgorzata Górska-Paukszta ${ }^{2, B, C}$,

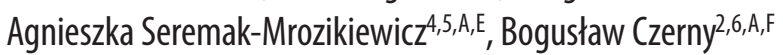 \\ ${ }^{1}$ Department of Orthopedics and Traumatology, Independent Public Clinical Hospital No. 1, Pomeranian Medical University, Szczecin, Poland \\ 2 Department of Stem Cells and Regenerative Medicine, Institute of Natural Fibers and Medicinal Plants, Plewiska, Poland \\ ${ }^{3}$ Department of Histocompatibility with Laboratory of Genetic Diagnostics, Regional Blood Center, Poznan, Poland \\ ${ }^{4}$ Division of Perinatology and Women's Diseases, Poznan University of Medical Sciences, Poland \\ ${ }^{5}$ Department of Pharmacology and Phytochemistry, Institute of Natural Fibres and Medicinal Plants, Plewiska, Poland \\ ${ }^{6}$ Department of Pharmacology and Pharmacoeconomics, Pomeranian Medical University, Szczecin, Poland \\ A - research concept and design; B - collection and/or assembly of data; $C$ - data analysis and interpretation; \\ $\mathrm{D}$ - writing the article; $\mathrm{E}$ - critical revision of the article; $\mathrm{F}$ - final approval of the article
}

\section{Address for correspondence \\ Adam Kamiński}

E-mail:adam.kaminski.848@gmail.com

\section{Funding sources}

The study was supported with statutory projects from the Institute of Natural Fibres and Medicinal Plants and the Pomeranian Medical University in Szczecin, Poland.

Conflict of interest

None declared

Received on November 20, 2017

Reviewed on May 20, 2018

Accepted on February 7, 2019

Published online on March 11, 2019

Cite as

Kamiński A, Bogacz A, Górska-Paukszta M, SeremakMrozikiewicz A, Czerny B. Correlation of rs749292 and rs700518 polymorphisms in the aromatase gene (CYP19A1) with osteoporosis in postmenopausal Polish women. Adv Clin Exp Med. 2019;28(8):1067-1071.

doi:10.17219/acem/103803

DOI

10.17219/acem/103803

\section{Copyright}

Copyright by Author(s)

This is an article distributed under the terms of the Creative Commons Attribution Non-Commercial License (http://creativecommons.org/licenses/by-nc-nd/4.0/)

\section{Abstract}

Background. The aromatase gene (CYP19A7) is responsible for the aromatization of androgenic precursors to estrogens in peripheral tissues - including bone - after menopause.

Objectives. The aim of this study was to evaluate the genotypes and allele frequencies of the rs749292 and rs700518 polymorphisms of the CYP19A1 gene in Polish postmenopausal women with osteopenia and osteoporosis. The potential correlations between genetic polymorphisms, bone mineral density (BMD), risk for bone fractures, and other clinical parameters were analyzed.

Material and methods. The study included 675 unrelated women (109 women with osteopenia, 333 women with osteoporosis, and 233 healthy women). Genomic DNA was extracted from the blood samples and the CYP19A1 polymorphisms were determined using the polymerase chain reaction restriction fragment length polymorphism (PCR-RFLP) method. Bone mineral density at the lumbar spine (L1-L4) was measured with dual energy $X$-ray absorptiometry (DEXA).

Results. The analysis of the CYP19A1 rs749292 polymorphism showed that there were no statistically significant differences in the distribution of genotypes between the study groups with osteoporosis and osteopenia and the control group. However, it was noted that the $\mathrm{GG}$ genotype occurred more often in the group with osteopenia (35.8\%; OR $=1.44$ ) than in the control group (27.9\%). Also, a difference was noted in the distribution of genotypes in women with osteoporosis. In addition, it can be assumed that the $\mathrm{G}$ allele may lead to an increased susceptibility to osteopenia and osteoporosis. The analysis of the CYP19A1 rs700518 polymorphism showed that heterozygotes were more common in the group with osteoporosis (58.3\%) than in the control group (52.8\%).

Conclusions. Our results suggest that the rs749292 polymorphism of the CYP19A1 gene may contribute to an elevated risk for fractures in postmenopausal Polish women.

Key words: postmenopausal osteoporosis, gene polymorphism, bone mineral density, CYP19A1 


\section{Introduction}

Osteoporosis is a common disease in postmenopausal women and is characterized by reduced bone mass resulting in an increased risk of fractures. Furthermore, it has been demonstrated that bone mass is highly dependent on genetic and environmental factors. ${ }^{1}$ Sex steroid hormones also have an important influence on bone mass. ${ }^{2}$ The main source of estrogens in women after menopause is the aromatization of androgenic precursors. The conversion of androgens to estrogens is catalyzed in a variety of tissues and aromatase (CYP19A1) is the key enzyme in this transformation. ${ }^{3,4}$ It is known that the loss of bone mass occurs due to the age-related loss of gonadal function. The CYP19A1 gene is located on $15 \mathrm{q} 21.2$ and contains 10 exons; exons 2 to 10 are transcribed and translated to create the aromatase enzyme. ${ }^{5-8}$

Importantly, it has been demonstrated that the various polymorphisms in the CYP19A1 gene may positively or negatively correlate with aromatase activity, sex hormone levels, bone mineral density (BMD) values, and fractures. ${ }^{9-14}$ Therefore, polymorphisms of genes regulating hormone production and metabolism may potentially explain the etiology of osteoporosis. The aim of this study was to examine the potential effects of the rs749292 and rs700518 polymorphisms in the CYP19A1 gene on osteoporosis in postmenopausal women. To our knowledge, there are no studies on the relationship between the CYP19A1 rs749292 polymorphism and osteoporosis development in postmenopausal women.

\section{Material and methods}

\section{Patients}

The study was comprised of 675 unrelated Polish women, including 109 women with osteopenia, 333 women with osteoporosis, and 233 healthy women. All of the women were in a postmenopausal age. During an interview with each patient, data on the occurrence of diseases, the age of first and last menstruation, the number of pregnancies, birth weight, and current height and weight were collected. Then, the body mass index (BMI) was calculated for each patient. The inclusion criteria for genetic research included the following: the onset of menopause at least 1 year prior to the study and the lack of hormone replacement therapy (HRT) or medications that affect bone mass - such as selective estrogen receptor modulators (SERMs), calcitonin, biphosphates, heparin, steroids, thyroid hormones, antiepileptics, GnRH analogues, or tibolone. Patients with diseases which influence bone metabolism - such as endocrine and metabolic disorders, hematological diseases, cancer, connective tissue diseases, and autoimmune disorders - were excluded from the study. Additionally, the postmenopausal patients did not suffer from hypoestrogenism at reproductive age or the premenopausal period. This study also disqualified patients who had undergone bilateral ovariectomy and patients with premature ovarian insufficiency (POI). Moreover, vitamin D and calcium intake either in the diet or as a supplement was advised per current clinical practice, but their use was not recorded among the patients studied.

The BMD measurements were performed at the Laboratory of Densitometry in Clinical Hospital No. 1 of the Pomeranian Medical University in Szczecin, Poland. Bone mineral density was measured at the lumbar vertebrae and the femoral neck using the dual-energy $\mathrm{x}$-ray absorptiometry method (DEXA) and a LUNAR DPX 100 densitometer (Lunar Corp., Madison, USA). All subjects underwent DEXA screening of lumbar vertebrae 2 to 4 (L2-L4). Bone mineral density values are presented as T-scores and Z-scores. Based on these measurements, the women were classified into 3 groups: those with osteopenia $(-2.5<\mathrm{T}$-score $<-1)$, those with osteoporosis (T-score $<-2.5)$ and those with a normal T-score (T-score $>-1$ ).

Among the patients studied, we did not observe the occurrence of any fractures, though - based on the BMD and bone turnover values in some patients - there was a risk of fracture. In addition, serum estradiol levels were not measured in the patients because the study assumed that postmenopausal patients with osteoporosis would have decreased levels of estrogen. The characteristics of the study population (postmenopausal women with osteopenia, osteoporosis or normal T-scores) are presented in Table 1.

The study was approved by the Local Bioethical Committee of the Pomeranian Medical University in Szczecin, Poland. All patients were informed about the purpose of the study and provided written informed consent.

\section{Analysis of CYP19A1 polymorphisms}

Blood samples were collected in the Department of Orthopedics and Traumatology at the Pomeranian Medical University. The analysis of CYP19A1 gene polymorphisms was conducted at the Department of Stem Cell and Regenerative Medicine at the Institute of Natural Fibers and Medicinal Plants in Poznań, Poland. Genomic DNA was extracted from peripheral blood using a QIAamp Blood Kit (Qiagen GmbH, Hilden, Germany) according to the manufacturer's instructions.

CYP19A1 rs749292 (A>G, TaqI) and rs700518 (G>A, RsaI) variants were determined by polymerase chain reaction restriction fragment length polymorphism (PCR-RFLP). The following primers were used for PCR: CYP19A1TaqIF: 5'-GCC ACC TGT CTC TCA TTC CA-3', CYP19A1TaqIR: 5-CTC CGT GAT TTG TCA GCT CTT-3' (386 bp), CYP19A1RsaIF: 5'-AGT AAC ACA GAA CAG TTG CA-3', and CYP19A1RsaIR: 5'-TCC AGA CTC GCA TGA ATT CTC CGT A-3' (188 bp). The polymorphic sites were defined using restriction enzymes for the CYP19A1 gene, such as TaqI 
Table 1. Characteristics of the study population (postmenopausal women with osteopenia, osteoporosis, or a normal T-score)

\begin{tabular}{|c|c|c|c|c|}
\hline Patients' characteristics & $\begin{array}{c}\text { Osteopenia } \\
\text { mean }( \pm 95 \% \mathrm{Cl})\end{array}$ & $\begin{array}{l}\text { Osteoporosis } \\
\text { mean }( \pm 95 \% \mathrm{Cl})\end{array}$ & $\begin{array}{c}\text { Controls, } \\
\text { mean }( \pm 95 \% \mathrm{Cl})\end{array}$ & p-value \\
\hline Age [years] & $53.2377( \pm 1.4553)$ & $56.0643( \pm 1.4760)$ & $53.3788( \pm 2.0206)$ & $\begin{array}{c}0.54^{\mathrm{a}} \\
0.014^{\mathrm{b}}\end{array}$ \\
\hline Height [cm] & $162.6311( \pm 0.8926)$ & $160.2527( \pm 1.0504)$ & $163.0758( \pm 1.4701)$ & $\begin{array}{l}0.08^{\mathrm{a}} \\
0.01^{\mathrm{b}}\end{array}$ \\
\hline Weight [kg] & $65.1721( \pm 1.9699)$ & $61.2088( \pm 1.8626)$ & $68.7273( \pm 2.9815)$ & $\begin{array}{l}0.026^{a} \\
0.001^{b}\end{array}$ \\
\hline BMI & $24.6445( \pm 0.7077)$ & $23.7879( \pm 0.6314)$ & $25.8802( \pm 1.1117)$ & $\begin{array}{l}0.04^{\mathrm{a}} \\
0.04^{\mathrm{b}}\end{array}$ \\
\hline Birth weight [g] & $3226.7857( \pm 159.3961)$ & $3141.2500( \pm 285.7844)$ & $3628.9474( \pm 231.7143)$ & $\begin{array}{l}0.026^{a} \\
0.005^{b}\end{array}$ \\
\hline Reproductive years & $36.2000( \pm 1.2743)$ & $35.6154( \pm 1.2418)$ & $36.3750( \pm 1.9291)$ & $\begin{array}{l}0.724^{\mathrm{a}} \\
0.528^{\mathrm{b}}\end{array}$ \\
\hline $\begin{array}{l}\text { Age of first menstruation } \\
\text { [years] }\end{array}$ & $13.1167( \pm 0.6184)$ & $12.9385( \pm 0.5362)$ & $13.3750( \pm 0.6776)$ & $\begin{array}{l}0.636^{a} \\
0.754^{b}\end{array}$ \\
\hline $\begin{array}{l}\text { Age of last menstruation } \\
\text { [years] }\end{array}$ & $49.2099( \pm 0.9868)$ & $48.1585( \pm 1.0905)$ & $50.1707( \pm 1.3847)$ & $\begin{array}{l}0.069^{a} \\
0.058^{b}\end{array}$ \\
\hline Number of pregnancies & $1.8852( \pm 0.1945)$ & $1.9560( \pm 0.2687)$ & $1.9394( \pm 0.2984)$ & $\begin{array}{l}0.869^{a} \\
0.902^{b}\end{array}$ \\
\hline Years after menopause & $7.1833( \pm 1.5562)$ & $10.6308( \pm 1.4245)$ & $7.0313( \pm 2.0156)$ & $\begin{array}{l}0.854^{\mathrm{a}} \\
0.001^{\mathrm{b}}\end{array}$ \\
\hline BMD L2- $L 4\left[\mathrm{~g} / \mathrm{cm}^{2}\right]$ & $0.9674( \pm 0.0398)$ & $0.9752( \pm 0.0296)$ & $0.9694( \pm 0.0439)$ & $\begin{array}{l}0.986^{a} \\
0.944^{b}\end{array}$ \\
\hline BMD L2-L4 YA [\%] & $80.9022( \pm 3.4153)$ & $81.2783( \pm 2.4579)$ & $81.0204( \pm 3.5647)$ & $\begin{array}{l}0.965^{\mathrm{a}} \\
0.982^{\mathrm{b}}\end{array}$ \\
\hline BMD L2-L4 AM [\%] & $89.1304( \pm 3.6295)$ & $89.5043( \pm 2.4379)$ & $89.7755( \pm 3.8959)$ & $\begin{array}{l}0.989^{a} \\
0.968^{b}\end{array}$ \\
\hline T-score & $-1.8520( \pm 0.0552)$ & $-3.1640( \pm 0.1118)$ & $0.0779( \pm 0.2261)$ & $<0001^{b}$ \\
\hline Z-score & $-0.8448( \pm 0.1694)$ & $-3.5691( \pm 3.8881)$ & $0.6425( \pm 0.4002)$ & $\begin{array}{l}0.117^{a} \\
<0001^{b}\end{array}$ \\
\hline
\end{tabular}

a - comparison between the group with osteopenia and the control group; ${ }^{b}$ - comparison between the group with osteoporosis and the control group; $95 \%$ $\mathrm{Cl}$-95\% confidence interval; BMI - body mass index; BMD - bone mineral density; BMD L2-L4 - bone mineral density of lumbar vertebrae 2 to 4; BMD-AM

L2-L4- age-matched bone mineral density of lumbar vertebrae 2 to 4; BMD L2-L4 YA - young-adults bone mineral density of lumbar vertebrae 2 to 4.

(AA: 327 bp, 59 bp; GG: 172bp, 155 bp, 59 bp) and RsaI (GG: $164 \mathrm{bp}, 24 \mathrm{bp}$; AA: $188 \mathrm{bp}$ ). The PCR-RFLP products were separated by electrophoresis according to their size in 3\% agarose gel with ethidium bromide and viewed under UV light.

\section{Statistical analysis}

Data analysis was performed using SPSS Statistics v. 17.0 software (SPSS Inc., Chicago, USA). The results are presented as mean values. The odds ratios (OR) are given with the respective $95 \%$ confidence intervals (95\% CI). The observed frequencies were compared with the expected frequencies and tested for Hardy-Weinberg equilibrium. The distribution of variables was evaluated with the Shapiro-Wilk test. The homogeneity of variances was assessed using the Levene test. Quantitative variables were compared with one-way analysis of variances (ANOVA) with post hoc contrast comparison tests. Ordinal data were compared with a $\chi^{2}$ test.

\section{Results}

Our analysis of the CYP19A1 rs749292 polymorphism showed that there were no statistically significant differences in the distribution of genotypes between women with osteoporosis or osteopenia and the control group ( $p=0.109)$. However, it is noticeable that the mutant GG genotype occurred more often in the group with osteopenia $(35.8 \%$; OR $=1.44$ ) than in the control group $(27.9 \%)$. Also, a difference was observed in the distribution of genotypes among the women with osteoporosis. Despite a lack of statistical significance between the groups, the wild homozygote (AA) occurred more frequently among the control group (23.2\%) than among the patients with osteopenia $(21.1 \%)$ or those with osteoporosis $(17.7 \%)$ (Table 2 ). There was only 1 statistically significant difference among the clinical parameters - the correlation between BMI and genotype in the osteopenia group $(\mathrm{p}=0.049)$ - although this was not observed in the patients with osteoporosis. On the basis of these results, it can be assumed that 
Table 2. Distribution of the CYP19A1 (rs749292) polymorphism in women with osteopenia, osteoporosis, and normal T-scores

\begin{tabular}{|c|c|c|c|c|c|c|c|c|c|}
\hline \multirow[b]{2}{*}{ Genotype } & \multicolumn{2}{|c|}{ Osteopenia } & \multicolumn{2}{|c|}{ Osteoporosis } & \multicolumn{2}{|c|}{ Control } & \multicolumn{3}{|c|}{ Statistical analysis } \\
\hline & $\begin{array}{c}\text { observed } \\
\text { values } \\
\text { n [\%] }\end{array}$ & $\begin{array}{c}\text { expected } \\
\text { values } \\
{[\%]}\end{array}$ & $\begin{array}{c}\text { observed } \\
\text { values } \\
\text { n [\%] }\end{array}$ & $\begin{array}{l}\text { expected } \\
\text { values } \\
{[\%]}\end{array}$ & $\begin{array}{l}\text { observed } \\
\text { values } \\
n[\%]\end{array}$ & $\begin{array}{l}\text { expected } \\
\text { values } \\
{[\%]}\end{array}$ & OR & $95 \% \mathrm{Cl}$ & $\mathrm{p}$-value \\
\hline AA & $23(21.1)$ & 18.2 & $59(17.7)$ & 20.8 & $54(23.2)$ & 22.6 & $\begin{array}{l}0.89^{a} \\
0.71^{b}\end{array}$ & $\begin{array}{l}0.49-1.58^{a} \\
0.46-1.11^{b}\end{array}$ & $\begin{array}{l}0.39^{a} \\
0.07^{b}\end{array}$ \\
\hline$A G$ & $47(43.1)$ & 48.9 & $186(55.9)$ & 49.6 & $114(48.9)$ & 49.9 & $\begin{array}{l}0.79^{a} \\
1.32^{b}\end{array}$ & $\begin{array}{l}0.49-1.28^{a} \\
0.93-1.87^{b}\end{array}$ & $\begin{array}{l}0.19^{a} \\
0.06^{b}\end{array}$ \\
\hline GG & $39(35.8)$ & 32.9 & $88(26.4)$ & 29.6 & 65 (27.9) & 27.5 & $\begin{array}{l}1.44^{\mathrm{a}} \\
0.92^{\mathrm{b}}\end{array}$ & $\begin{array}{l}0.86-2.40^{a} \\
0.63-1.37^{b}\end{array}$ & $\begin{array}{l}0.09^{a} \\
0.38^{b}\end{array}$ \\
\hline Total & 109 (100) & 100.00 & $333(100)$ & 100.00 & $233(100)$ & 100.00 & - & - & - \\
\hline \multicolumn{10}{|c|}{ Alleles } \\
\hline A & $93(42.7)$ & - & $304(45.6)$ & - & $222(47.6)$ & - & $\begin{array}{l}0.82^{\mathrm{a}} \\
0.92^{\mathrm{b}}\end{array}$ & $\begin{array}{l}0.58-1.15^{a} \\
0.72-1.18^{b}\end{array}$ & $\begin{array}{l}0.13^{\mathrm{a}} \\
0.27^{\mathrm{b}}\end{array}$ \\
\hline G & $125(57.3)$ & - & $362(54.4)$ & - & $244(52.4)$ & - & $\begin{array}{l}1.22^{\mathrm{a}} \\
1.08^{\mathrm{b}}\end{array}$ & $\begin{array}{c}0.87-1.71^{a} \\
0.85-1.38^{b}\end{array}$ & $\begin{array}{l}0.13^{a} \\
0.27^{b}\end{array}$ \\
\hline Total & $218(100.00)$ & - & $666(100.00)$ & - & $466(100.00)$ & - & - & - & - \\
\hline
\end{tabular}

a comparison between the group with osteopenia and the control group; ${ }^{b}$ - comparison between the group with osteoporosis and the control group; OR - odds ratio; $95 \% \mathrm{Cl}-95 \%$ confidence interval.

Table 3. Distribution of the CYP19A1 (rs700518) polymorphism in women with osteopenia, osteoporosis, and normal T-scores

\begin{tabular}{|c|c|c|c|c|c|c|c|c|c|}
\hline \multirow[b]{2}{*}{ Genotype } & \multicolumn{2}{|c|}{ Osteopenia } & \multicolumn{2}{|c|}{ Osteoporosis } & \multicolumn{2}{|c|}{ Control } & \multicolumn{3}{|c|}{ Statistical analysis } \\
\hline & $\begin{array}{l}\text { observed } \\
\text { values } \\
n[\%]\end{array}$ & $\begin{array}{l}\text { expected } \\
\text { values } \\
{[\%]}\end{array}$ & $\begin{array}{l}\text { observed } \\
\text { values } \\
\text { n [\%] }\end{array}$ & $\begin{array}{l}\text { expected } \\
\text { values } \\
{[\%]}\end{array}$ & $\begin{array}{l}\text { observed } \\
\text { values } \\
\text { n [\%] }\end{array}$ & $\begin{array}{l}\text { expected } \\
\text { values } \\
{[\%]}\end{array}$ & OR & $95 \% \mathrm{Cl}$ & $p$-value \\
\hline AA & $27(24.8)$ & 25.9 & $83(24.9)$ & 29.3 & 65 (27.9) & 29.5 & $\begin{array}{l}0.85^{a} \\
0.85^{b}\end{array}$ & $\begin{array}{l}0.48-1.47^{a} \\
0.58-1.28^{b}\end{array}$ & $\begin{array}{l}0.32^{a} \\
0.24^{b}\end{array}$ \\
\hline$A G$ & $57(52.3)$ & 50.0 & $194(58.3)$ & 49.7 & $123(52.8)$ & 49.6 & $\begin{array}{l}0.98^{a} \\
1.25^{b}\end{array}$ & $\begin{array}{l}0.61-1.58^{a} \\
0.88-1.77^{b}\end{array}$ & $\begin{array}{l}0.51^{a} \\
0.11^{b}\end{array}$ \\
\hline$G G$ & $25(22.9)$ & 24.1 & $56(16.8)$ & 21.0 & 45 (19.3) & 20.9 & $\begin{array}{l}1.24^{a} \\
0.84^{b}\end{array}$ & $\begin{array}{l}0.68-2.23^{a} \\
0.53-1.34^{b}\end{array}$ & $\begin{array}{l}0.26^{a} \\
0.25^{b}\end{array}$ \\
\hline Total & 109 (100) & 100.00 & $333(100)$ & 100.00 & $233(100)$ & 100.00 & - & - & - \\
\hline \multicolumn{10}{|c|}{ Alleles } \\
\hline A & $111(50.9)$ & - & $360(54.1)$ & - & $253(54.3)$ & - & $\begin{array}{l}0.87^{a} \\
0.99^{b}\end{array}$ & $0.62-1.22^{a}$ & $0.22^{a}$ \\
\hline G & $107(49.1)$ & - & 306 (45.9) & - & $213(45.7)$ & - & $\begin{array}{l}1.15^{\mathrm{a}} \\
1.01^{\mathrm{b}}\end{array}$ & $\begin{array}{l}0.82-1.60^{a} \\
0.77-1.26^{b}\end{array}$ & $\begin{array}{l}0.22^{a} \\
0.49^{b}\end{array}$ \\
\hline Total & $218(100.00)$ & - & $666(100.00)$ & - & $466(100.00)$ & - & - & - & - \\
\hline
\end{tabular}

OR - odds ratio; 95\% Cl - 95\% confidence interval.

the $\mathrm{G}$ allele (mutant) may lead to an increased susceptibility to osteopenia and osteoporosis.

In our analysis of the CYP19A1 rs700518 polymorphism, there were no statistically significant differences in the distribution of genotypes between the groups with osteoporosis and osteopenia and the control group $(\mathrm{p}=0.520)$. It was observed that heterozygotes were more common among the women with osteoporosis (58.3\%) than in the control group (52.8\%), but the difference was not statistically significant (Table 3). There were some statistically significant differences between clinical parameters and genotypes. Correlations were observed between genotype and BMI $(p=0.049)$, age $(p=0.035)$, and years after menopause $(\mathrm{p}=0.012)$ in the patients with osteopenia. Osteopenia occurred at an earlier age (49.9 years) in the patients with the mutant AA genotype than in those with the GG (53.1 years) and GA (54.9 years) genotypes $(\mathrm{p}=0.035)$. Also, a statistically significant difference was observed between genotype and age-matched bone mineral density (BMD-AM) $(\mathrm{p}=0.042)$. The lowest BMD-AM was observed in patients with the recessive AA genotype. The BMD-AM values were higher among the women with the GG and GA genotypes. These results indicate a trend of a higher probability of osteopenia in the recessive homozygotes.

There were no statistically significant differences in genotype frequency among patients with osteoporosis, but a correlation did appear between the genotype and reproductive years $(\mathrm{p}=0.042)$. 


\section{Discussion}

In this study, we observed no statistically significant effects of CYP19A1 polymorphisms on the occurrence of osteopenia and osteoporosis. No differences were noted in the distribution of the CYP19A1 rs749292 genotype between patients and controls. However, the GG genotype occurred more often in women with osteopenia than in the control group. Available studies indicate that genetic variations of the CYP19A1 gene, including rs749292, are associated with hormone levels in postmenopausal women with breast cancer. ${ }^{15,16}$ At the same time, while no data is available (according to our knowledge and literature review) on the allele and genotype frequencies for CYP19A1 rs749292 in postmenopausal women with osteopenia/osteoporosis compared to controls, results similar to ours were obtained by Yilmaz et al. ${ }^{17}$ The authors of that study investigated the frequencies of the CYP19A1 rs700518 polymorphism in patients with osteoporosis and a control group from the Turkish population. They did not observe a relationship between the studied polymorphism and the occurrence of osteoporosis, though they did report a higher occurrence of the AG genotype (63\%) among the control group. This relationship could have resulted from the limited size of the study group. They also pointed out the lower frequency of AA and AG genotypes among the patients. In our study, the AA genotype also occurred less frequently in osteoporotic patients (16.8\%) compared with the control group (19.3\%). However, the differences were not statistically significant $(\mathrm{OR}=0.84 ; 95 \% \mathrm{CI}=0.53-1.34 ; \mathrm{p}=0.25)$.

Furthermore, Geng et al. found no significant effect of the rs700518 polymorphism on BMD in the Chinese population among postmenopausal women. ${ }^{18}$ Similarly, in our study the GA genotype (44.5\%) occurred most frequently, while the homozygous GG and AA genotypes accounted for $19.5 \%$ and $36 \%$, respectively. The CYP19A1 rs700518 polymorphism was also reported to be associated with differences in BMD and hormone levels in men $(n=1068)$. Lorentzon et al. showed that men with the GG genotype had higher BMD values than carriers of the AG and AA genotypes. ${ }^{1}$ Similar statistically significant results ( $\mathrm{p}=0.010)$ were obtained by Riancho et al. ${ }^{11}$ Total hip BMD was the highest in patients with the GG genotype $\left(0.823 \mathrm{~g} / \mathrm{cm}^{3}\right)$ and was accordingly lower in those with the GA $\left(0.807 \mathrm{~g} / \mathrm{cm}^{3}\right)$ and AA $\left(0.795 \mathrm{~g} / \mathrm{cm}^{3}\right)$ genotypes.

In our study, we also observed the same relationship between genotype and AM-BMD values ( $p=0.042)$ among female patients with osteopenia (89.3 for GG, 91.9 for GA and 78.9 for AA). Napoli et al. ${ }^{14}$ conducted a study on women taking the aromatase inhibitor during breast cancer therapy and showed that patients with the AA genotype developed significant bone loss relative to patients carrying the $G$ allele (GA and GG genotypes). These findings may suggest that the A allele leads to more susceptibility to bone loss during therapy and that the GG genotype has a protective influence.

\section{Conclusions}

Our results suggest that the rs749292 polymorphism of the CYP19A1 gene may contribute to an elevated risk for fractures in Polish postmenopausal women.

\section{References}

1. Lorentzon M, Swanson C, Eriksson AL, Mellström D, Ohlsson C. Polymorphisms in the aromatase gene predict areal BMD as a result of affected cortical bone size: The GOOD study. J Bone Miner Res. 2006;21(2):332-339.

2. Carson JA, Manolagas SC. Effects of sex steroids on bones and muscles: Similarities, parallels, and putative interactions in health and disease. Bone. 2015;80:67-78.

3. Riancho JA, Valero C, Naranjo A, Morales DJ, Sanudo C, Zarrabeitia MT. Identification of an aromatase haplotype that is associated with gene expression and postmenopausal osteoporosis. Clin Endocr Metab. 2007;92(2):660-665.

4. Shimodaira M, Nakayama T, Sato N, et al. Association study of aromatase gene (CYP19A1) in essential hypertension. Int JMed Sci. 2008;5(1):29-35.

5. Bulun SE, Sebastian S, Takayama K, Suzuki T, Sasano H, Shozu M. The human CYP19 (aromatase P450) gene: Update on physiologic roles and genomic organization of promoters. J Steroid Biochem Mol Biol. 2003;86(3-5):219-224.

6. Leelawattana R, Ziambaras K, Roodman-Weiss J, et al. The oxidative metabolism of estradiol conditions postmenopausal bone density and bone loss. J Bone Miner Res. 2000;15(12):2513-2520.

7. Masi L, Becherini L, Gennari L, et al. Polymorphism of the aromatase gene in postmenopausal Italian women: Distribution and correlation with bone mass and fracture risk. J Clin Endocrinol Metab. 2001;86(5):2263-2269.

8. Somner J, McLellan S, Cheung J, et al. Polymorphisms in the P450 c17 (17-hydroxylase/17,20-Lyase) and P450 c19 (aromatase) genes: Association with serum sex steroid concentrations and bone mineral density in postmenopausal women.J Clin EndocrinolMetab. 2004;89(1):344-351.

9. Gennari L, Masi L, Merlotti D, et al. A polymorphic CYP19 TTTA repeat influences aromatase activity and estrogen levels in elderly men: Effects on bone metabolism. J Clin Endocrinol Metab. 2004;89(6):2803-2810.

10. Riancho JA, Zarrabeitia MT, Valero C, et al. Aromatase gene and osteoporosis: Relationship of ten polymorphic loci with bone mineral density. Bone. 2005;36(5):917-925.

11. Riancho JA, Sanudo C, Valero C, et al. Association of the aromatase gene alleles with BMD: Epidemiological and functional evidence. J Bone Miner Res. 2009;24(10):1709-1718.

12. Zarrabeitia MT, Hernández JL, Valero C, et al. A common polymorphism in the 5 '-untranslated region of the aromatase gene influences bone mass and fracture risk. Eur J Endocrinol. 2004;150(5):699-704.

13. Tofteng $\mathrm{CL}$, Kindmark $\mathrm{A}$, Brändström $\mathrm{H}$, et al; Danish Osteoporosis Prevention Study. Polymorphisms in the CYP19 and AR genes - relation to bone mass and longitudinal bone changes in postmenopausal women with or without hormone replacement therapy: The Danish Osteoporosis Prevention Study. Calcif Tissue Int. 2004;74(1):25-34.

14. Napoli N, Rastelli A, Ma C, et al. Genetic polymorphism at Val80 (rs700518) of the CYP19A1 gene is associated with aromatase inhibitor associated bone loss in women with $\mathrm{ER}+$ breast cancer. Bone. 2013;55(2):309-314.

15. Kopp TI, Jensen DM, Ravn-Haren G, et al. Alcohol-related breast cancer in postmenopausal women: Effect of CYP19A1, PPARG and PPARG$C 1 A$ polymorphisms on female sex-hormone levels and interaction with alcohol consumption and NSAID usage in a nested case-control study and a randomized controlled trial. BMC Cancer. 2016;16:283.

16. Flote VG, Furberg AS, McTiernan A, et al. Gene variations in estrogen pathways, CYP19A1, daily $17 \beta$-estradiol and mammographic density phenotypes in premenopausal women. Breast Cancer Res. 2014;16:499.

17. Yilmaz MB, Pazarbasi A, Guzel Al, et al. Association of serum sex steroid levels and bone mineral density with CYP17 and CYP19 gene polymorphisms in postmenopausal women in Turkey. Genet Mol Res. 2011;10(3):1999-2008.

18. Geng L, Yao ZW, Luo JY, Han LL, Lu Q. Association between Val80 polymorphism of the CYP19 gene, A163G polymorphism of the OPG gene and bone mineral density in post-menopausal Chinese women [in Chinese]. Yi Chuan. 2007;29(11):1345-1350. 